\title{
Physician adherence to guidelines for tuberculosis and HIV care in Rio de Janeiro, Brazil
}

\begin{abstract}
Background: Tuberculosis is the most common opportunistic infection among HIV-infected patients in Brazil. Brazil's national policy for HIV care recommends screening for latent tuberculosis (TB) and implementing isoniazid preventive therapy (IPT). Objectives: We compared physician adherence to TB screening and other prevention and care policies among HIV primary care clinics in Rio de Janeiro City. Methods: Data on performance of CD4 counts, viral load testing, tuberculin skin testing (TST) and IPT were abstracted from patient charts at 29 HIV clinics in Rio de Janeiro as part of the TB/HIV in Rio (THRio) study. Data on use of pneumocystis jiroveci pneumonia (PCP) prophylaxis were also abstracted from a convenience sample of 150 patient charts at $10 \mathrm{HIV}$ clinics. Comparisons were made between rates of adherence to TB guidelines and other HIV care guidelines. Results: Among the subset of 150 patients with confirmed HIV infection in 2003, 96\% had at least one reported CD4 counts result; $93 \%$ had at least one viral load result reported; and, PCP prophylaxis was prescribed for $97 \%$ of patients with CD4 counts $<200$ cells $/ \mathrm{mm}^{3}$ or when clinically indicated. In contrast, 67 patients (45\%) had a TST performed (all eligible); and only 11\% (17) of eligible patients started IPT. Among 12,027 THRio cohort participants between 2003 and 2005, the mean number of CD4 counts and viral load counts was 2.5 and 1.9, respectively, per patient per year. In contrast, $49 \%$ of 8,703 eligible patients in THRio had a TST ever performed and only 53\% of eligible patients started IPT. Conclusion: Physicians are substantially more compliant with HIV monitoring and PCP prophylaxis than with TB prophylaxis guidelines. Efforts to improve TB control in HIV patients are badly needed.
\end{abstract}

Keywords: AIDS-related opportunistic infections; tuberculosis; disease prevention; guideline adherence.

[Braz J Infect Dis 2011;15(3):249-252] @Elsevier Editora Ltda.

\section{INTRODUCTION}

Tuberculosis (TB) is the most common opportunistic infection among HIV-infected patients in Brazil. ${ }^{1}$ Among reported AIDS cases in Rio de Janeiro city, TB is diagnosed within one year in $15-18 \%,{ }^{2}$ and TB is the cause of death in approximately $10 \%$ of all AIDS deaths. ${ }^{3}$ The universal availability of HAART in Brazil has led to a reduction in the incidence of opportunistic diseases such as Pneumocystis jiroveci pneumonia (PCP), ${ }_{4}^{4}$ but has had much less of an impact on TB. ${ }^{2}$

Brazil's national policy for HIV care recommends at least three CD4-cell counts and viral load measurements per year, regardless of antiretroviral use. Annual screening for latent TB infection with a tuberculin skin test (TST) and provision of isoniazid preventive therapy (IPT) for patients with a TST result $>5 \mathrm{~mm}$ of induration is also recommended. In addition, HIV-infected patients with WHO stages 3 or 4 disease or a CD4-cell count $<200 / \mathrm{mm}^{3}$ should receive co-trimoxazole prophylaxis for $\mathrm{PCP}^{5}$

Physician adherence to guidelines varies by disease and is often dependent on a variety of factors. ${ }^{6,7}$ For AIDS and HIV infection, guidelines first appeared early in the epidemic, ${ }^{8}$ focusing primarily on diagnostic and preventive measures. In recent years, focus has moved towards monitoring and treatment of HIV infection with antiretroviral (ARV) agents. A previous report showed that Brazilian physicians have good adherence to national guidelines, but the study mainly focused on ARV management. ${ }^{9}$ Little information has been available regarding adherence to TB-related guidelines in HIV-infected patients in Brazil.

We compared physician adherence to guidelines for HIV-infected patients in Brazil, with special attention to latent TB screening and provision of isoniazid preventive therapy versus other HIV care policies.
Authors

Valeria Saraceni ${ }^{1}$

Antonio Guilherme Pacheco

Jonathan E Golub ${ }^{3}$

Vitoria Vellozo

Bonnie S King

Solange C Cavalcante

Lois Eldred $^{7}$

Richard E Chaisson ${ }^{8}$

Betina Durovni ${ }^{9}$

${ }^{\mathrm{M}} \mathrm{MD}, \mathrm{PhD}$; Technical Manager at SINAN, SMSDC-Rio de Janeiro, RJ, Brazil

${ }^{2} \mathrm{PhD}$; Researcher PROCC Fiocruz, Rio de Janeiro, RJ, Brazil

${ }^{3} \mathrm{PhD}$; Center for Tuberculosis Research, Johns Hopkins University School of

Medicine and Department of Epidemiology, Johns Hopkins Bloomberg School of Public

Health, Baltimore,

Maryland, USA

${ }^{4} \mathrm{PhD}$; Assistant, SIAP, SMSDCRio de Janeiro, RJ, Brazil ${ }^{5} \mathrm{MPH}$; Center for Tuberculosis Research, Johns Hopkins University School of Medicine ${ }^{6} \mathrm{PhD}$; Assistant, SIAP, SMSDCRio de Janeiro, RJ, Brazil ${ }^{7} \mathrm{MD}$; Center for Tuberculosis Research, Johns Hopkins University School of Medicine, Baltimore, Maryland, USA ${ }^{8} \mathrm{MD}$; Center for Tuberculosis Research, Johns Hopkin University School of Medicine and Department of Epidemiology, Johns Hopkin Bloomberg School of Public Health, Baltimore, Maryland, USA ${ }^{9} \mathrm{MPH}$; Superintendent, SIAP, SMSDC-Rio de Janeiro,

RJ, Brazil

Submitted on: 11/24/2010 Approved on: 02/06/2011

Correspondence to: Valeria Saraceni Rua Afonso Cavalcanti, 455 sala 809

Cidade Nova - Rio de Janeiro RJ - Brasil CEP 20211-901 valsaraceni@gmail.com

Financial Support: Bill and Melinda Gates Foundation grant for the Consortium to Respond Effectively to the AIDS-TB Epidemic (CREATE).

We declare no conflict of interest. 


\section{METHODS}

The study was conducted within the TB/HIV in Rio de Janeiro (THRio) study, a cluster randomized trial promoting TST and use of IPT in HIV clinics in Rio de Janeiro, Brazil. ${ }^{10}$ Clinical and laboratory data, including CD4-cell count, viral load, TST, and IPT data, are regularly abstracted from patient charts at 29 HIV clinics participating in THRio study. Trained abstractors used standardized data collection forms to obtain information on all patients seen in the HIV clinics after September $1^{\text {st }} 2003$, and accuracy was assured by reabstraction and routine quality control measures. For the current analysis, we used data collected in the first round of chart abstractions in 2005-2006, covering clinical care for all patients active from the start of the study until the date of abstraction. To obtain data on provision of PCP prophylaxis, which is not part of the THRio database, we abstracted additional information from the charts of 150 patients at 10 of the study clinics using a structured data collection tool. The patients represent a convenience sample of 15 medical charts at each health center among patients seen on the day prior to data collection.

We considered all patients receiving HIV care in the clinics to be eligible to receive CD4 and viral load monitoring, which was recommended thrice annually regardless of stage of disease or use of antiretroviral therapy. According to guidelines, patients eligible for TST were those without a prior history of active TB or a positive TST in the past, and each eligible patient was to be tested at least once annually. IPT was considered indicated in those with TST results $>5 \mathrm{~mm}$ induration and without active TB disease. Co-trimoxazole prophylaxis was considered indicated in patients with a CD4 count $<200 / \mathrm{mm}^{3}$ or with WHO stage 3 or 4 disease. ${ }^{5}$

Descriptive statistical analysis compared adherence with specific guidelines either in the entire sample or within the subset of 150 patients for whom PCP prophylaxis data were available.

\section{RESULTS}

Among the 12,027 HIV-infected patients in the THRio database with follow up between September $1^{\text {st }} 2003$ and September 1st 2005, 95\% $(11,403 / 12,027)$ had at least one reported CD4 count and $94 \%$ had at least one reported viral load result. The rate of CD4 cell counts per person was $2.5 /$ year and the rate of viral load quantifications per person was 1.9/year. In contrast, 4,804 of 8,703 (49\%) patients eligible to have a TST placed had one prior to the initiation of the study. Of those with positive tests and no active TB, 778 (53\%) were given IPT (Table 1).

Among the 150 patients in our convenience sample, all had indications for PCP prophlyaxis at some point in time and 145 (97\%) had received co-trimoxazole. Ninetysix percent of patients (144) had at least one reported CD4 and $93 \%$ (139) had at least one reported viral load; mean time between a request for CD4 and viral load tests and its registration in the chart was 3.7 months. For 111 patients (74\%), lipid levels were recorded and reference to adherence to therapy was found in 108 charts (81\%). In contrast, $67 \mathrm{pa}$ tients (45\%) had a tuberculin skin test performed and only $11 \%$ patients started IPT ever (Table 2).

Table 1. Mean number of CD4 and viral load tests per year and proportion of patients with a TST applied per year, THRio cohort

\begin{tabular}{lcc}
\hline Test & No. patients tested/number eligible & Mean number per patient or proportion \\
\hline CD4-count & $11,403 / 12,027$ & $2.52 \mathrm{p} /$ year* $^{*}$ \\
\hline Viral load & $11,264 / 12,027$ & $1.94 \mathrm{p} /$ year* $^{*}$ \\
\hline TST & $4,804 / 8,703$ & $16.2 \% /$ year \\
\hline
\end{tabular}

* National guidelines recommend at least 3 per year

Table 2. Proportion of HIV-infected patients receiving care recommended by national guidelines, Rio de Janeiro, Brazil $(n=150)$

\begin{tabular}{lcc}
\hline Guidelines & Proportion & Number/n eligible \\
\hline PCP prophylaxis & 97 & $145 / 150$ \\
\hline CD4 results & 96 & $144 / 150$ \\
\hline Viral load results & 93 & $139 / 150$ \\
\hline TST applied & 45 & $67 / 150$ \\
\hline IPT & 11 & $17 / 150$
\end{tabular}

\section{DISCUSSION}

Our study has shown that physician adherence to HIV guidelines in Rio de Janeiro City is quite high for PCP prophylaxis and moderate to low with routine monitoring of standard HIV clinical markers. However, adherence is quite poor for detection and treatment of latent tuberculosis infection among HIV-infected patients. Rio de Janeiro City has a high burden of tuberculosis ${ }^{11}$ and a relatively low HIV prevalence in the general population. ${ }^{4} \mathrm{~TB}$ is the most common opportunistic infection among HIV-positive 
patients and TB accounts for almost $10 \%$ of the underlying cause of death among those reported as AIDS cases. ${ }^{3}$ Despite this burden, detection and treatment of latent tuberculosis infection is relatively ignored by HIV/AIDS physicians.

In the pre-antiretroviral era, PCP was the most important cause of sickness and death in the HIV epidemic, and prescribing co-trimoxazole was quickly seen as a life saving action. ${ }^{12}$ In our study, $97 \%$ of the patients had been prescribed a PCP prophylaxis drug, most commonly co-trimoxazole, when their CD4 counts were below 200 cells $/ \mathrm{mm}^{3}$ or when the patient had symptoms related to HIV progression and no CD4 results available. Thus, physicians have continued to prescribe this preventive medication according to guidelines. Using targeted physician feedback, Montaner et al. ${ }^{13}$ showed an increase in adherence to guidelines for PCP prevention from $29 \%$ to $61 \%$ and an increase in TST provision from $43 \%$ to $65 \%$ in Vancouver, Canada between 1990 and 1993. However, baseline data collected for the THRio study ${ }^{14}$ revealed a low proportion of patients receiving TST and IPT, despite guidelines recommending these measures since $1994 .^{1}$

Many barriers have been described while looking for physician non-adherence to well-established evidence-based clinical protocols. ${ }^{7}$ Our findings are in concordance with studies conducted in other settings, both in the developed ${ }^{15-17}$ and developing countries. ${ }^{18}$ Physicians did not request a TST for 36\% of eligible HIV positive patients in New York City in $1995^{15}$ and Lee et al..$^{16}$ found a slightly higher proportion (46\%) of patients without a TST in three other US cities. In both studies, an association between having a TST placed and a greater number of visits to clinics was reported and in New York City, an association with a written clinic policy for TST screening in HIV positive patients was detected. ${ }^{16}$ A survey among physicians with 630 respondents in San Francisco Area Bay, US (350 of which were involved in HIV care), suggested that physician's experience in HIV care predicted adherence to IPT guidelines ${ }^{18}$ while a similar finding was reported in Italy though $29 \%$ still did not receive a TST. ${ }^{17}$ In Thailand, only $19 \%$ of physicians provided IPT to their patients despite a national recommendation for provision of IPT for people living with HIV. ${ }^{19}$ Moreover, they were not attentive to excluding active TB, as only $35 \%$ of the doctors requested a chest $\mathrm{x}$-ray prior to IPT initiation.

Placement of a tuberculin skin test followed by IPT when indicated requires a commitment both from physicians and patients, as more clinic visits are required and adherence to another medication must be considered. Ruling out active TB is a requirement before starting IPT and includes symptom screening, sputum smear microscopy and a chest radiograph. These extra steps may discourage a physician from testing for latent TB infection. Furthermore, in a qualitative study done with physicians in Rio de Janeiro, ${ }^{20}$ concerns about isoniazid toxicity were the reason stated for not ad- hering to guidelines. Although there is evidence of the low toxicity of isoniazid among HIV patients, ${ }^{21}$ and the efficacy of IPT in reducing tuberculosis has been shown, ${ }^{14}$ fear of toxicity ${ }^{22}$ and ruling out active disease likely contribute to the poor uptake.

There are some limitations for our study. First, the convenience sample was a small one when compared to the study, but it allowed us to get important information both on PCP and TB prophylaxis, which resulted in more discussion about both topics in the TB/HIV training activities that were implemented in the 29 clinics during to the study. Second, no data on PCP prophylaxis was collected thereafter for follow-up on the comparison. On the other hand, this study was critical to establish the baseline level of TST and IPT coverage in those clinics.

Thus, the efficacy of IPT at reducing the burden of TB among HIV-positive patients must be disseminated among doctors and the HIV community. Furthermore, the process of ruling out TB should be seen as an opportunity to detect active cases of TB for early treatment and reduction of mortality and transmission of TB. New evidence from the WHO should alleviate some of the fears associated with ruling out active TB disease. ${ }^{23}$

\section{REFERENCES}

1. Jamal LF, Moherdaui F. Tuberculosis and HIV infection in Brazil: magnitude of the problem and strategies for control. Rev Saúde Pública 2007; 41 Suppl 1:104-10.

2. Pacheco AG, Durovni B, Cavalcante SC et al. AIDS-related tuberculosis in Rio de Janeiro, Brazil. PLoS ONE 2008; 3:e31-2.

3. Saraceni V, King BS, Golub JE, Lauria LM, Cavalcante SC, Durovni B. Tuberculosis as primary cause of death among AIDS cases in Rio de Janeiro City, Brazil. Int J Tuberc Lung Dis 2008; 12:769-72.

4. Secretaria Municipal de Saúde do Rio de Janeiro. Gerência do Programa de DST/AIDS. Rio de Janeiro; 2008. Accessed from [http://www.saude.rio.rj.gov.br/aids/].

5. Brazil. Ministry of Health. Recommendations on Antiretroviral Therapy in HIV-infected Adults and Adolescents. Brasilia; 2008.

6. Brand C, Landgren F, Hutchinson A, Jones C, Macgregor L, Campbell D. Clinical practice guidelines: barriers to durability after effective early implementation. Intern Med J 2005; 35:162-9.

7. Cabana MD, Rand CS, Powe NR et al. Why don't physicians follow clinical practice guidelines? A framework for improvement. JAMA 1999; 282:1458-65.

8. Centers for Disease Control and Prevention (CDC). Current Trends Prevention of Acquired Immune Deficiency Syndrome (AIDS): Report of Inter-Agency Recommendations. MMWR 1983; 32:101-3.

9. Nemes MI, Carvalho HB, Souza MF. Antiretroviral therapy adherence in Brazil. AIDS 2004; 18(Suppl 3):S15-20.

10. Moulton L, Golub JE, Durovni B et al. Statistical design of THRio: a phased implementation clinic-randomized study of a tuberculosis preventive therapy intervention. Clin Trials 2007; 4:190-9. 
11. Secretaria Municipal de Saúde do Rio de Janeiro. Gerência do Programa de Pneumologia Sanitária. Rio de Janeiro; 2008. Accessed from [http://www.saude.rio.rj.gov.br/tuberculose/].

12. Sackoff J, McFarland J, Su S, Bryan E. Prophylaxis for opportunistic infections among HIV-infected patients receiving medical care. J Acquir Immune Defic Syndr Hum Retrovirol 1998; 19:387-92.

13. Montaner JS, Phillips P, Zala C, Craib KJ, O’Shaughnessy MV, Schechter MT. Adherence to guidelines for the prevention of HIV-related respiratory diseases. Eur Respir J 1996; 9:2318-22.

14. Golub JE, Saraceni V, Cavalcante SC et al. The impact of antiretroviral therapy and isoniazid preventive therapy on tuberculosis incidence in HIV-infected patients in Rio de Janeiro, Brazil. AIDS 2007; 21:1441-8.

15. Sackoff JE, Torian LV, Frieden TR, Brudney KF, Menzies IB. Purified protein derivative testing and tuberculosis preventive therapy for HIV-infected patients in New York City. AIDS 1998; 12:2017-23.

16. Lee LM, Lobato MN, Buskin SE, Morse A, Costa S. Low adherence to guidelines for preventing TB among persons with newly diagnosed HIV infection, United States. Int J Tuberc Lung Dis 2006; 10:209-14.
17. Antonucci G, Girardi E, Raviglione $\mathrm{M}$ et al. Guidelines of tuberculosis preventive therapy for HIV-infected persons: a prospective, multicentre study. Eur Respir J 2001; 18:369-75.

18. De Riemer K, Daley CL, Reingold AL. Preventing tuberculosis among HIV-infected patients: a survey of physicians' knowledge and practices. Prev Med 1999; 28:437-41.

19. Hiransuthikul N, Hiransuthikul P, Nelson KE, Jirawisit M, Paewplot R, Kasak S. Physician adherence to isoniazid preventive therapy guidelines for HIV-infected patients in Thailand. Southeast Asian J Trop Med Public Health 2005; 36:1208-15.

20. Vellozo V, Israel G, Saraceni V, Ferreira RCM, Durovni B, DeLuca A. THRio qualitative study (Abstract PS-82357-20). In: Program and abstracts: 38th Union World Conference on Lung Health Paris: France, 2008.

21. Churchyard GJ, Scano F, Grant AD, Chaisson RE. Tuberculosis preventive therapy in the era of HIV infection: overview and research priorities. J Infect Dis 2007; 196 Suppl 1:S52-62.

22. Snider DE Jr, Caras GJ. Isoniazid-associated hepatitis deaths: a review of available information. Am Rev Respir Dis 1992; 145:494-7.

23. WHO. WHO Three I's Meeting: Report of a Joint WHO HIV/ AIDS and TB Department Meeting. Geneva, Switzerland: WHO, 2008. 